\title{
A GRAMÁTICA EM SALA DE AULA - O QUE DIZEM PROFESSORES E ALUNOS
}

Mary Neiva Surdi da Luz ${ }^{1}$

Resumo: $O$ ensino de Língua Portuguesa tem sido um tema de investigação há algumas décadas e os resultados obtidos são, na maioria das vezes, desanimadores. Neste texto, apresentamos resultados de pesquisas realizadas pelo Grupo de Pesquisa Estudos Lingüísticos e Literários, vinculado à Unochapecó-SC. As pesquisas realizadas têm como sujeitos alunos e professores vinculados à rede pública de ensino e apesar de se tratarem de pesquisas realizadas em tempos e com sujeitos diferentes, nos traçam um quadro do ensino de gramática na instituição escolar, no tempo presente.

Palavras-chave: gramática, ensino, professores de língua, discentes, ensino médio.

\section{Palavras iniciais}

A inserção da pesquisa no campo escolar ainda causa desconforto para muitos. Em especial, para professores e direções. Há uma certa mitologia em torno dos propósitos de uma pesquisa. Para alguns, a pesquisa tem como função "crucificar" os envolvidos, apontando seus "erros", "falhas" e "deficiências". Dos que pensam assim, não se obtêm muita colaboração.

No entanto, há também os que vêem na pesquisa uma fonte para analisar e reavaliar o processo de ensino aprendizagem e além de colaborar, solicitam o retorno dos resultados. Mas os que mais colaboram e se sentem gratificados são os alunos. Durante a aplicação dos questionários, pôde-se perceber a imensa satisfação que os discentes sentiam por participarem de uma "pesquisa", palavra que para eles ainda não representa perigo. Também há alguns professores que colaboram e vêem na pesquisa uma forma de poder discursivizar suas práticas, falar sobre suas experiências e auxiliar nas reflexões sobre o ensino.

\footnotetext{
1 Doutoranda em Letras/Estudos Lingüísticos UFSM/PPGL/Laboratório Corpus, sob orientação da prof ${ }^{a}$ Dr. Amanda Eloina Scherer; Professora da Unochapecó, SC.
} 
Para este texto selecionamos os resultados de duas pesquisas. A primeira, O Ensino de Língua Portuguesa no Ensino Médio das Escolas da Rede Estadual de Chapecó-SC, realizada pela acadêmica Mari Léa Rosa Ferreira, em 2003, em que foram entrevistados 220 alunos da rede pública estadual, e a segunda, Concepções Teóricas e Metodológicas que Norteiam o Ensino de Língua Portuguesa, realizada pela acadêmica Juliane Kuhn, em 2006, em que foram ouvidos nove professores de Língua Portuguesa que atuam na rede pública estadual. Passemos aos resultados.

\section{O que dizem os alunos de ensino médio sobre o ensino de gramática}

Para a coleta de dados com os discentes, foi utilizada como ferramenta metodológica a aplicação de questionários. Os questionários consistiam em uma série de perguntas, entregues por escrito aos informantes que deveriam respondê-las por escrito também. Para a aplicação dos questionários, foi realizado o contato inicial que, segundo RUDIO (1992), é de grande importância para motivar e preparar o informante, a fim de que suas respostas sejam realmente sinceras e adequadas. A aplicação definitiva se deu nos meses de abril e maio de 2003, com a aplicação de 220 questionários. Os dados obtidos nos questionários foram classificados, codificados, tabulados e analisados. Depois de tabulados, os dados foram analisados quantitativa e qualitativamente e também articulados ao referencial teórico e confrontados aos objetivos do estudo a fim de se ver seu significado para a pesquisa.

Em relação ao estudo da gramática, os alunos foram questionados sobre sua importância e observamos que enquanto $42 \%$ dos alunos consideram o estudo da gramática necessário, especialmente, para preparar os alunos para o vestibular, $58 \%$ não o consideram.

Possivelmente, esse número é fruto da experiência que os alunos têm com o ensino gramatical e das expectativas que tal ensino gera:

$42 \%$ partem da idéia de que é preciso dominar um saber sobre a língua; dominar um conhecimento metalingüístico que os habilite a passar em um vestibular ou em um concurso público; 
$>58 \%$ lembram do estudo de regras
descontextualizadas, exercícios isolados, "salada" nomenclaturas etc. Toda experiência negativa faz com que o aluno não veja sentido em estudar a organização interna da língua, pois não aprendeu a relacionar tal estudo ao uso lingüístico.

Quando questionados sobre como é realizado o trabalho de estudo da gramática nas aulas de Língua Portuguesa constata-se que a seqüência apresentada pelo livro didático determina, em $36 \%$, a forma como se estuda a gramática na sala de aula.

Observa-se que $33 \%$ dos alunos responderam que a gramática é estudada, a partir de regras e exercícios. De acordo com Naspolini (1996), essa prática pedagógica está fundamentada na crença que exercícios estanques ou isolados de determinados assuntos podem instrumentalizar o aluno para fazer uso desses conhecimentos na hora de produzir seus textos. Porém, o que ocorre é que o aluno faz os exercícios, acerta-os, mas nem sempre consegue aplicar os conhecimentos em situações textuais.

Em relação à mesma questão, 31\% dos alunos responderam que a gramática é trabalhada através da análise lingüística de suas produções. Geraldi (1993) argumenta que, através do trabalho com textos dos alunos, podem ser comparados os recursos expressivos usados pelos alunos e os recursos expressivos mais próprios da assim chamada língua culta. Com a análise lingüística podem ser trabalhados problemas de ordem estrutural, sintática, morfológica e fonológica.

Com a expressão "análise lingüística" pretendo referir-me precisamente a este conjunto de atividades que tomam uma das características da linguagem como seu objeto: o fato de ela poder remeter a si própria, ou seja, com a linguagem não só falamos sobre o mundo ou sobre nossa relação com as coisas, mas também falamos sobre como falamos (GERALDI, 1993, p. 189-190).

Ao se trabalhar a gramática a partir dos textos, não adianta utilizar textos como pretextos, ou seja, apenas retirando-se deles palavras ou frases soltas, é preciso que o estudo da gramática seja visto em uso e para o uso, inserido em situações reais.

\section{O que dizem os professores}

A Gerência de Educação, Ciência e Tecnologia - Chapecó (GECT) atende a 11 municípios do oeste catarinense: Águas Frias, 
Caxambú do Sul, Chapecó, Cordilheira Alta, Coronel Freitas, Guatambú, Nova Erechim, Nova Itaberaba, Planalto Alegre, Serra Alta e Sul Brasil. Foram selecionados, por indicação voluntária, um professor de Língua Portuguesa de cada uma das escolas dos municípios, excetuando-se o município de Chapecó, no qual não foi possível realizar a coleta (em função do tempo disponível para a realização da pesquisa que coincidiu com um período de greve), num total de nove professores. Os critérios para seleção dos professores para a composição do corpus foram estar em curso ou ter concluído de curso superior e atuação nas séries finais do ensino fundamental.

A pesquisa foi realizada com professores de nove dos onze municípios da região abrangida pela Gerência de Educação, Ciência e Tecnologia - Chapecó. Dos municípios, excetuaram-se Chapecó, pelo pouco tempo disponível para a realização das entrevistas, e Guatambú, em que os professores não puderam disponibilizar um horário.

Todo e qualquer falante tem sua gramática intuitiva, mesmo que não saiba definir as classes de palavras, sabe que, para formar um diálogo coerente, precisa organizar as palavras conforme uma classificação implícita. Os conceitos gramaticais, na escola, se reduzem às questões metalingüísticas de definição e classificação das unidades da língua: a subdivisão das conjunções e os respectivos nomes de cada uma; a classificação de cada tipo de oração e a subclassificação de cada subclasse de pronomes. A escola, desse modo, pretende que o aluno saiba "o nome que as coisas têm." "A escola perde muito tempo com questões de mera nomenclatura e de classificação, enquanto o estudo das regras dos usos da língua em textos fica sem vez, fica sem tempo." (ANTUNES, 2003, p. 88).

O foco das aulas de língua deve ser a própria língua ou algo mais abrangente, a linguagem, em suas manifestações discursivas. Não somente a linguagem imutável, descrita atemporalmente, mas uma linguagem em constante modificação, seguindo o movimento da história humana, em que os sujeitos são parte de um ciclo. Tornase necessário o espaço para uma linguagem aberta à interlocução que se promove na "singularidade do sujeito em constituição". O princípio específico deve ser a mudança. O processo interlocutivo se desenvolve a partir da (re)construção da linguagem. Também é importante salientar que a linguagem é feita para/pelos e com os outros, tornando-se, assim, um trabalho social. Há que se 
considerar, portanto, que a interação presente no processo de desenvolvimento da linguagem não é algo situado fora de um contexto social e histórico.

\section{Como trabalham com a gramática}

Quando perguntados sobre como desenvolvem seu trabalho com a gramática $44 \%$ dos professores entrevistados responderam que trabalham com a gramática dentro do texto, explorando tópicos gramaticais que os alunos aprendem ao longo de sua vida escolar e que podem reconhecer dentro do texto. De uma certa forma, é o texto sendo utilizado como pretexto para trabalhar a gramática. E aí o que se vê são verdadeiros genocídios textuais e discursivos: não se dá atenção nem aos aspectos que caracterizam cada gênero textual e muito menos à discursividade. $O$ que acontece é somente uma mudança de suporte: em vez de se estudar a gramática naquele livro pesado e desconfortável de manusear, se utiliza uma folha, ou duas, em que tudo parece estar mais ou menos resumido. Mas também é preciso parar de "jogar as pedras" e tentar compreender por que isso acontece. E posso dizer, fazendo referência a uma passagem bíblica, que alguém entre nós é um traidor, mas sem quer sê-lo: o próprio lingüista. Desde o final da década de 80 , quando as teorias lingüísticas apregoaram que o ensino de língua deveria ter como objeto de trabalho o texto e que a gramática deveria ser estudada a partir de textos, dos próprios alunos ou então de autores já consagrado, "fez-se o caos". Como mesmo fazer isso? Como se estuda a gramática em um texto? Para muitos professores, esse seria o verdadeiro mistério da nossa fé.

$12 \%$ dos professores dizem trabalhar conceitos gramaticais em conteúdos separados por séries. E aqui algumas perguntas são pertinentes: qual é o conteúdo adequado para cada série? Quais são os critérios utilizados para dizer em que série se estuda tal ou tal conteúdo? Haveria alguma relação então idade cronológica e escolar com a capacidade de conhecer e estudar a língua? Os conteúdos podem ser repetidos em mais de uma série? Talvez se obtivesse como resposta a essa última pergunta a idéia de que os conteúdos podem ser os mesmos, o que mudaria seria o grau de aprofundamento dado em cada série. Indo do mais fácil para o mais difícil, do mais simples para o mais complexo. Respondam-se então, sem pestanejar, em língua: o que é simples? O que é fácil? O que é complexo? É possível aplicar esses atributos à língua? Para finalizar, 
$22 \%$ dizem trabalhar prioritariamente com a gramática normativa e $22 \%$ afirmaram que não priorizam o trabalho com a gramática e que trabalham mais com textos.

O que mais chama a atenção é que, por mais que os professores tenham contato com as propostas de estudo da linguagem de modo interacionista, ainda insistem em um trabalho baseado na gramática normativa. Quando afirmam trabalhar a gramática dentro do texto tomam uma parte da proposta interacionista para sua prática em sala de aula. Porém, essa parte ainda não é o bastante para a formação do aluno, para que ele deixe a escola utilizando plenamente sua competência lingüística.

Além disso, muitas vezes os textos utilizados nas aulas para o trabalho com a gramática são textos literários. Em alguns casos, o próprio livro didático traz a orientação de textos bem escritos por autores bastante conhecidos, tomando suas obras como exemplos de bom uso da gramática da língua. Conforme Rocha, a língua literária (principalmente da literatura atual) se caracteriza pelo desvio à norma, como uma possibilidade de extrapolar as regras.

A língua literária contemporânea caracteriza-se, portanto, pela possibilidade de rebeldia com relação à tradição gramatical, não podendo, portanto, ser considerada como modelo para a língua padrão. [...] Por outro lado, também não faz sentido eleger a língua literária dos séculos anteriores como modelo da língua padrão atual, como fazem as gramáticas tradicionais. (ROCHA, 2002, p. 59-60).

Para que o aluno saia da escola dominando sua língua, sentindo-se seguro quanto ao seu uso, é necessário que conheça diversas formas dessa língua, sendo que a língua padrão é considerada um importante aporte para a comunicação social. Ao invés de ser um incômodo na trajetória escolar, a gramática deveria ser um auxílio para uma boa formação discente.

Entretanto, há práticas que apenas consideram a gramática no seu aspecto formal, como aquela ligada à norma culta da língua, vê-se a língua como se ela fosse algo estático, estagnado, bem diferente da língua falada, sempre num movimento contínuo. Segundo Antunes,

de tudo que diz respeito à língua, a nomenclatura é a parte menos móvel, menos flexível, mais estanque e mais distante das intervenções dos falantes. Talvez, por isso mesmo, seja a parte 
'mais fácil' de virar objeto das aulas de língua. (ANTUNES, 2003, p. 32).

As ações em sala de aula devem se orientar para um ponto comum e relevante: conseguir ampliar as competências comunicativo-interacionais dos alunos. O conhecimento teórico de alguns professores se limita à gramática da língua. Falta às suas aulas uma fundamentação teórica baseada no aprofundamento de como funciona a linguagem humana, "como se tudo o que é uma língua em funcionamento coubesse dentro do que é uma gramática" (ANTUNES, 2003, p. 40).

\section{Referências Bibliográficas}

ANTUNES, I. Aula de Português: Encontro \& Interação. São Paulo: Parábola, 2003.

GERALDI, J. W. Portos de Passagem. 2. ed. São Paulo: Martins Fontes, 1993.

NASPOLINI, A. T. Didática de Português: Tijolo por Tijolo. Leitura e Produção Escrita. São Paulo: FTD, 1996.

ROCHA, L. C. Gramática: Nunca Mais. O Ensino da Língua Padrão sem o Estudo da Gramática. Belo Horizonte: UFMG, 2002.

RUDIO, F. V. Introdução ao Projeto de Pesquisa Científica. Petrópolis: Vozes, 1992. 